\title{
INVOLUNTARY REDUCTION IN VIGOUR OF CALVES BORN FROM SEXED SEMEN
}

\author{
Radica DJedović ${ }^{1}$, Vladan Bogdanović ${ }^{1}$, Dragan StanojeVić ${ }^{1}$, Zsolt NeMES ${ }^{1}$, \\ András GÁSPÁRDY ${ }^{2 *}$ and Sándor $\mathrm{CSEH}^{3}$ \\ ${ }^{1}$ Faculty of Agriculture, University of Belgrade, Belgrade-Zemun, Serbia; ${ }^{2}$ Department \\ of Animal Breeding and Genetics, Institute for Animal Breeding, Nutrition and Laboratory \\ Animal Science and ${ }^{3}$ Department and Clinic of Reproduction, Faculty of Veterinary \\ Science, Szent István University, István u. 2, H-1078 Budapest, Hungary
}

(Received 13 August 2015; accepted 28 October 2015)

The objective of this study was to compare the reproductive traits of heifers and the development characteristics of their calves following artificial insemination (AI) with sexed and non-sexed semen. The analysed characteristics included conception rate, gestation length, calf birth weight, calf vigour, stillbirth rate, and twinning rate. Data of 530 calves produced with sexed and 1,163 calves produced with non-sexed semen were analysed. The General Linear Model (GLM) was applied to assess the influence of semen type, farm, season of insemination, the calf's sex and the inseminating sire on gestation length and calf birth weight. With the exception of gestation length $(\mathrm{P}>0.05)$, all other traits studied were significantly $(\mathrm{P}<0.01)$ influenced by the type of semen. The conception rate was $55 \%$ for conventional and $44 \%$ for sexed semen, and the average gestation length was 274.6 and 274.9 days, respectively. The mean calf birth weight was $37.47 \mathrm{~kg}$ for non-sexed and $36.75 \mathrm{~kg}$ for sexed semen. The stillbirth rate was $6.19 \%$ for conventional and $7.54 \%$ for sexed semen, while the twinning rate was $3.78 \%$ for conventional and $1.13 \%$ for sexed semen. The calves produced with non-sexed and sexed semen differed significantly in viability $(\mathrm{P}<0.001)$, the latter having a lower calf vigour score. The use of conventional semen did not affect the ratio of female and male calves (52.7:47.3\%; P > 0.05); however, artificial insemination with $\mathrm{X}$-sorted sexed semen significantly altered the sex ratio of calves $(85.1: 14.9 \%$, $\mathrm{P}<0.01)$. The results obtained in this investigation are in agreement with the majority of studies which compared the fertility traits, sex ratio and calf characteristics depending on the application of artificial insemination with sexed or conventional semen.

Key words: Sexed semen, conventional semen, heifers, fertility traits, sex ratio, calf vigour

Compared to the use of conventional artificial insemination, the utilisation of sexed semen in dairy cattle breeding accelerates genetic progress as a greater

*Corresponding author; E-mail: Gaspardy.Andras@aotk.szie.hu;

Phone: 0036 (1) 478-4120; Fax: 0036 (1) 478-4124

0236-6290/\$ 20.00 (C) 2016 The Authors 
number of offspring of the desired sex can be produced in a shorter period of time (Seidel, 2007; De Vries et al., 2008). Many field studies (Seidel, 2003; Cerchiaro et al., 2007; DeJarnette et al., 2009; Norman et al., 2010) achieved around $90 \%$ female offspring by separating the spermatozoa.

Seidel et al. (1999) reported that the pregnancy rate in Holstein heifers ranged from $21 \%$ to $35 \%$ for sexed semen compared with $58 \%$ for conventional semen. A lower fertility rate with sexed semen was also reported by several other researchers (Seidel and Garner, 2002; Tubman et al., 2004; Norman et al., 2010; DeJarnette et al., 2011; Healy et al., 2013). This lower fertility is due to damages caused to spermatozoa by the physical forces during the sexing process as they are placed under high pressure at great speed with abrupt deceleration (Seidel, 2003). It is therefore recommended that sexed semen be primarily used in heifers showing distinct signs of oestrus (Foote, 2010). Heifers are the most fertile animals in the herd and good fertility of the recipient is of crucial importance when using sexed semen. Furthermore, heifers are not yet burdened by lactation.

There is a possibility that early embryonic mortality rate in calves produced by use of sexed semen is slightly elevated (Seidel et al., 1999; Tubman et al., 2004; Healy et al., 2013). However, no increase in abnormalities in calves born from sexed semen relative to controls has been reported to date.

The objective of this paper was to compare the reproductive traits of heifers and the development characteristics of their calves following artificial insemination with sexed and non-sexed semen.

\section{Materials and methods}

\section{Study design and animals}

This was a retrospective study using data on 3,320 inseminations of improved Black Pied Lowland heifers, raised on six commercial dairy farms of the Agricultural Corporation of Belgrade, in central Serbia from January 2012 to January 2014. All heifers in the breeding programme were raised under the same conditions (large groups of contemporaries in open housing system). Heifers were nutritionally managed to attain an average daily weight gain of 0.55 to $0.65 \mathrm{~kg}$ from birth to breeding. The main components of their ration were corn silage, alfalfa hay, canola meal, wheat bran and feed additives, and later on they were fed on a total mixed ration which was introduced after their first calving. The average milk yield of these farms was around $8,000 \mathrm{~kg}$.

\section{Reproductive management}

On all farms, artificial insemination (AI) was performed with the semen of purebred Holstein bulls $(n=26)$. Sixty $\%$ of AIs were performed with the semen 
of bulls progeny tested in Serbia, while $40 \%$ were done with imported semen of breeding bulls, mainly from the USA and Canada. The sexed semen originated exclusively from Cooperative Resources International (CRI, Wisconsin, USA) and was sorted by flow cytometry, with an aim to produce semen with a ratio skewed in favour of gynosperms as female calves are preferred in the dairy herd.

All 26 sires were selected for improvement in milk production and calving ease.

Artificial insemination was carried out daily, on the same morning as the detection of oestrus by AI technicians. Sperm viability and semen quality were not evaluated before insemination and as such, the results reflect normal on-farm reproductive management. In most cases, sex-sorted semen straws were used only for the first or second breeding, and heifers returning to oestrus were inseminated subsequently with conventional semen. The site of sperm deposition was the uterine body. Inseminated heifers were tested for pregnancy via rectal palpation from 40 to 50 days post insemination, and no pregnant heifers were inseminated again upon return to oestrus.

\section{Collected data}

The total number of inseminations was 3,320. The numbers of inseminations performed with sexed and non-sexed (conventional) semen were 1,205 and 2,115 , respectively. The conventional semen dosages came from 20 sires, while the sexed semen was derived from the remaining six sires in this study.

Besides the individual identification number (ID) of the heifers, the mated sires and the calves born, the following raw data were collected: date of inseminations, date of conception, date of calving, type of semen (sexed or non-sexed), calf sex, calf birth weight.

The statistical evaluation was expanded to the following properties: conception rate, gestation length, birth weight, calf vigour, neonatal mortality (stillbirth), twinning rate, and sex ratio.

The conception rate was expressed as the proportion of successful inseminations. The gestation length was calculated as the interval between the date of conception and the date of calving in days. The birth weight was measured within the first $24 \mathrm{~h}$ post partum (pp) in $\mathrm{kg}$ to one decimal place. Calf vigour was scored on a five-point scale ( 1 - calf with inborn anomalies, 2 - poorly developed and non-viable calf, 3 - moderately developed and vital calf, 4 - well-developed calf, 5 - vital calf). Stillbirths included calves that were born dead or died within $48 \mathrm{~h}$. All stillborn calves were recorded, but their sex was not determined. The incidence of multiple births was also recorded at the calving. The sex ratio used in this study is the secondary sex ratio which is the relative frequency of male and female offspring at the moment of birth. 


\section{Statistical analysis}

Upon combining and revising the records obtained from various farms we determined the differences in the properties investigated according to the two types of semen (sexed or non-sexed) which were used in the course of inseminations.

The chi-square $\left(\chi^{2}\right)$ test (Statistical Analysis System; SAS Institute, Inc., Cary, NC) with a significance set at $\mathrm{P} \leq 0.05$ was used to compare the conception rate, calf vigour, stillbirth, twinning rate and sex ratio in relation to semen type.

To analyse the length of gestation and the birth weight a factorial least squares ANOVA with Type III sums of squares was performed using the GLM procedures of the same SAS (SAS, 2013). Here, the type of semen, farm, season of conception, sex of calf, and sire were studied as possible sources of variation for the traits investigated. The following generalised linear model (GLM) was used to evaluate the effects:

$$
\mathrm{Y}_{\mathrm{ijklm}}=\mu+\mathrm{T}_{\mathrm{i}}+\mathrm{F}_{\mathrm{j}}+\mathrm{S}_{\mathrm{k}}+\mathrm{P}_{\mathrm{l}}+\mathrm{O}_{\mathrm{m}}+\mathrm{e}_{\mathrm{ijklm}}
$$

where:

$\mathrm{Y}_{\mathrm{ijklm}}$ - phenotypic manifestation of the studied trait,

$\mu \quad-$ general average of population,

$T_{i} \quad$ - fixed effect of the type of semen (i=1-2),

$F_{j} \quad$ - fixed effect of the $j^{\text {th }}$ farm $(j=1-6)$,

$\mathrm{S}_{\mathrm{k}} \quad$ - fixed effect of the $\mathrm{k}^{\text {th }}$ season of conception $(\mathrm{k}=1-4)$,

$\mathrm{P}_{1} \quad$ - fixed effect of the calf sex $(1=1-2)$,

$\mathrm{O}_{\mathrm{m}} \quad-$ fixed effect of the sire $(\mathrm{m}=1-26)$,

$\mathrm{e}_{\mathrm{ijk} l m}-$ random error.

\section{Results}

The mean values of the studied traits (and standard deviations in the case of parametric traits) according to the type of semen are presented in Table 1. The conception rate of heifers inseminated with conventional semen was $55 \%$ as compared to $44 \%$ with sexed semen; however, there was no significant difference in gestation length (274.6 vs. 274.9 days, respectively). Lower mean values of birth weight and vigour were observed in calves born from sexed semen. No anatomic abnormalities were observed in calves during the trial. Neonatal death was more frequent in calves born from sexed semen. Sex-sorted semen resulted in a remarkably lower twin frequency. All the differences between the means of the traits analysed (with the exception of gestation length) were statistically significant $(\mathrm{P}<0.01)$. 
Table 1

Mean values of studied traits according to the type of semen

\begin{tabular}{lcrrrr}
\hline Trait & \multicolumn{2}{c}{ Conventional semen (n) } & \multicolumn{2}{c}{ Sexed semen (n) } & P value \\
\hline Conception rate (\%) & 55 & $(2,115)$ & 44 & $(1,205)$ & $<0.001$ \\
Gestation length (days), mean \pm SD & $274.6 \pm 9.9$ & $(1,163)$ & $274.9 \pm 9.0$ & $(530)$ & $=0.492$ \\
Birth weight (kg), mean \pm SD & $37.5 \pm 2.5$ & $(1,163)$ & $36.8 \pm 2.0$ & $(530)$ & $<0.001$ \\
Calf vigour (score) & 4.5 & $(1,091)$ & 4.1 & $(490)$ & $<0.001$ \\
Stillbirth (\%) & 6.2 & $(72)$ & 7.5 & $(40)$ & $<0.001$ \\
Twin births (\%) & 3.8 & $(44)$ & 1.1 & $(6)$ & $<0.001$
\end{tabular}

Table 2 illustrates the effect and statistical significance of semen type, farm, season of insemination, calf sex and sire on gestation length and calf birth weight. Excluding semen type, the majority of the factors in the model had a highly significant impact on the studied traits, with both the season of conception and the sire having an effect approaching significance on the gestation length.

Table 2

Analysis of variance for gestation length and birth weight

\begin{tabular}{|c|c|c|c|c|}
\hline \multirow{2}{*}{ Trait/Source } & \multicolumn{4}{|c|}{ Gestation length (days) } \\
\hline & DF & MS & F value & $P$ value \\
\hline Semen type & 1 & 44.021756 & 0.51 & $=0.492$ \\
\hline Farm & 5 & 523.579663 & 6.12 & $<0.001$ \\
\hline Season & 3 & 216.410126 & 2.53 & $=0.056$ \\
\hline Calf sex & 2 & $1,932.813916$ & 22.58 & $<0.001$ \\
\hline Sire & 26 & 121.929896 & 1.42 & $=0.080$ \\
\hline \multirow[t]{2}{*}{ Error } & 1,654 & 85.5898 & & \\
\hline & \multicolumn{4}{|c|}{ Birth weight (kg) } \\
\hline Semen type & 1 & 184.906300 & 49.06 & $<0.001$ \\
\hline Farm & 5 & 122.531210 & 32.51 & $<0.001$ \\
\hline Season & 3 & 19.754216 & 5.24 & $=0.001$ \\
\hline Calf sex & 2 & 458.104676 & 121.55 & $<0.001$ \\
\hline Sire & 26 & 9.409893 & 2.50 & $<0.001$ \\
\hline Error & 1,654 & 3.768798 & & \\
\hline
\end{tabular}

$\mathrm{DF}=$ degree of freedom; MS = mean square

Table 3 compares the sex ratios resulting from insemination with the two types of semen, proven by the $\chi^{2}$-test. The use of conventional semen did not affect the proportion of male and female calves $(47.3 \%$ vs. $52.7 \%$; $\mathrm{P}>0.05)$, while sexed semen shifted the calf sex ratio to $14.9 \%$ vs. $85.1 \%(\mathrm{P}<0.001)$. 
Table 3

Sex ratio of calves according to the type of semen

\begin{tabular}{lcccc}
\hline Relative frequency $(\%)$ of & \multicolumn{2}{c}{ Conventional semen $(\mathrm{n}=1,091)$} & \multicolumn{2}{c}{ Sexed semen $(\mathrm{n}=490)$} \\
\hline males $(\mathrm{n})$ & 47.3 & $(516)$ & 14.9 & $(73)$ \\
females $(\mathrm{n})$ & 52.7 & $(575)$ & 85.1 & $(417)$ \\
$\chi^{2}$ value & 3.19 & & 241.50 & $<0.001$ \\
$\mathrm{P}$ value & $=0.596$ & & \\
\hline
\end{tabular}

Table 4 shows the gender frequency and gender distribution in twins according to the semen type. There was a significant reduction in the occurrence of female-female calf pairs $(33.3 \%$ with a theoretically expected value of about $75 \%$ ); however, the twin sample size was very small in the case of insemination with sexed semen.

\section{Table 4}

Frequencies of calf gender and calf pairs according to the type of semen and type of birth

\begin{tabular}{|c|c|c|c|c|c|c|}
\hline $\begin{array}{l}\text { Relative frequency }(\%) \text { of calves } \\
\text { in single births }(n=1,047) \text { : }\end{array}$ & \multicolumn{2}{|c|}{$\begin{array}{l}\text { Conventional semen } \\
\qquad(\mathrm{n}=1,091)\end{array}$} & \multicolumn{2}{|c|}{$\begin{array}{l}\text { Sexed semen } \\
(\mathrm{n}=490)\end{array}$} & $\chi^{2}$ value & $P$ value \\
\hline females (n) & 52.0 & $(544)$ & 85.3 & (413) & 17.93 & $<0.001$ \\
\hline males (n) & 48.0 & $(503)$ & 14.7 & (71) & 325.13 & $<0.001$ \\
\hline $\begin{array}{l}\text { in twin births }(\mathrm{n}=44) \text { : } \\
\text { female-female pairs }(\mathrm{n}\end{array}$ & & & & & & \\
\hline male-male pairs (n) & 4.5 & (2) & 0.0 & (0) & 2.00 & $<0.001$ \\
\hline female-male pairs (n) & 54.5 & (24) & 66.7 & (4) & 14.29 & $<0.001$ \\
\hline
\end{tabular}

\section{Discussion}

Previous studies have shown that conception rate as an indicator of the success of insemination with sexed semen is highly variable, and that it is lower compared to that obtained with conventional semen. Conception rate with sexed semen in this study (44\%) is in harmony with studies which reported 39 to $57 \%$ for heifers inseminated with sexed semen (Cerchiaro et al., 2007; DeJarnette et al., 2009) and higher than that reported by Weigel (2004), Bodmer et al. (2005) and Healy et al. (2013).

The lower conception rate obtained with sexed semen is most probably due to the damage of spermatozoa during the sorting process and the decreased concentration of spermatozoa in the applied doses (Seidel et al., 1999; Bodmer et al., 2005; Garner and Seidel, 2008). However, improvements of the sorting proc- 
ess can increase the conception rate and thus may contribute to a wider use of sexed semen in dairy cattle breeding in the future.

The conception rate obtained with conventional semen in this study $(55 \%)$ was remarkably higher than that established for Holstein heifers by Healy et al. (2013), and was in accordance with the majority of literature reports (Cerchiaro et al., 2007; DeJarnette et al., 2009; Norman et al., 2010) which cite rates as high as $75 \%$. At the same time, in a number of studies the highest conception rates were observed under moderate climate conditions similar to the prevailing climate of the region of this study.

Gestation length is a species-specific characteristic for every domestic animal and depends on a plethora of factors. Gestation length is also determined by the breed of the parents, particularly of the sire (O'Ferrall and Ryan, 1990; Cundiff et al., 1986; Gregory et al., 1997). The results obtained for gestation length were in agreement with several studies (DeJarnette et al., 2009; Norman et al., 2010) which report that gestation length in heifers is also significantly influenced by the season of insemination, the inseminating sire, the twinning frequency and the sex of the calf. Male sex prolongs the gestation length, and this is reflected in higher birth weight compared to female calves. The type of insemination did not significantly reduce or prolong the gestation length, neither in the aforementioned studies nor in the studies of Tubman et al. (2004) and Healy et al. (2013).

Studying the calf birth weight is important for several reasons. Among others, the high birth weight of calves is one of the major causes of dystocia and perinatal mortality. Calf birth weight is influenced by different genetic and nongenetic effects, such as calf sex, body mass and age of the dam and sire, number of calvings, calving season, breed, gestation length, and duration of the dry period (Nelsen et al., 1984; Cundiff et al., 1986). Both our study and that of Tubman et al. (2004) showed that in addition to the season of conception and the sire, the type of artificial insemination also significantly $(\mathrm{P}<0.01)$ affected the birth weight.

Calf vigour was estimated for all live-born calves with subjective scores from 1 to 5 . With this scoring system and partly due to the differences originating from dams, the calves produced by sexed and non-sexed semen differed significantly $(\mathrm{P}<0.001)$. Our results are different from those of Tubman et al. (2004) who found no significant difference in calf viability in relation to sex or semen type. Globally, many farmers are facing a constant increase in calf mortality rate, which has negative effects on the economy of milk production (Meyer et al., 2000; Steinbock et al., 2003; Zadeh et al., 2008).

The rate of single stillborn calves from heifers inseminated with conventional sperm in this research matches the results of Zadeh et al. (2008). Our rates of single stillborn calves from heifers inseminated with conventional and sexed semen were significantly different $(6.19$ and $7.54 \%$, respectively; $\mathrm{P}<0.01)$. The 
rates were also lower than $10.4 \%$ for conventional semen and $11.3 \%$ for sexed semen reported by Norman et al. (2010). Healy et al. (2013) recorded even higher rates of stillborn calves $(11.6 \%$ for conventional and $13.3 \%$ for sexed semen). These authors stated that the rate of stillborn offspring is influenced by sex, twinning, gestation length, AI technician, semen type, age of dam, and season of insemination. DeJarnette et al. (2009) suggested that the increased stillbirth rate of heifers inseminated with sexed semen was the consequence of the sorting process which damages the sperm and leads to reduced viability of the fetus and an increase in stillbirths.

In previous studies the twinning rates of Holstein and Black Pied Lowland heifers ranged from $0.76 \%$ to $1.3 \%$ (Mee, 1991; Zadeh et al., 2008; Norman et al., 2010). The twinning rate in this investigation was significantly higher than is expected for heifers of dairy breeds $(\mathrm{P}<0.001)$ and was dependent upon the type of semen. The use of sexed semen (Table 4) significantly increased the frequency of the female twin pairs at the expense of male twins, in agreement with the values reported by Tubman et al. (2004), Norman et al. (2010) and Healy et al. (2013).

Sex is determined by the random coupling of gametes during fertilisation and, therefore, the expected primary sex ratio is likely to approximate $1: 1$ in the offspring. By the application of sexed semen, heifers are expected to deliver female calves in about $90 \%$ of the cases in contrast to the $49 \%$ average frequency obtained with conventional semen (Seidel, 2003; Cerchiaro et al., 2007; DeJarnette et al., 2009; Norman et al., 2010).

The sex ratio achieved in this study with sexed semen was acceptable and similar to that reported by Bodmer et al. (2005) and Healy et al. (2013). However, it was somewhat lower than the $90 \%$ ratio of female calves reported in the literature.

The realised proportion of sexes can be considered to be the consequence of increased sorting speed with a resultant reduction in accuracy (Seidel, 2003). The sex ratio in Seidel's research was significantly $(\mathrm{P}<0.01)$ shifted by the application of sexed sperm. The inseminating sire also had a significant effect on the sex ratio (Norman et al., 2010; Healy et al., 2013). The sex ratio after insemination with conventional semen $(52.7 \%$ female) was in contrast to the 50 to $52 \%$ male calf births in the majority of published reports (Tubman et al., 2004; Zadeh et al., 2008; DeJarnette et al., 2009). However, Norman et al. (2010) reported the birth of only $48.5 \%$ male singles, which was similar to the findings of this investigation. It might be speculated that male fetuses tend to show a more pronounced mortality already before birth under the conditions of intensive dairy production.

The relative frequency of female calf pairs in this study lagged behind the values reported by Healy et al. (2013); however, we agree with the latter authors' comment that the use of sexed sperm increases the frequency of female pairs at the expense of male ones. 
The results obtained in this investigation are in agreement with the majority of studies which compared the fertility traits, sex ratio and calf characteristics depending on the application of AI with sexed or conventional semen. Based on our results we conclude that the application of sexed semen does not lead to any increase in calf abnormalities or change in gestation length, but it negatively affects the fertility rate and some calf characteristics such as birth weight, stillbirth rate, and calf vigour. Despite all this, sexed semen enables breeders to use only the best replacement heifers in the herd which thus improves the genetic base of the breeding stock. Sexed semen should be used only for the insemination of quality heifers on farms with reliable reproductive management, as otherwise fertility can decrease on farm level.

Despite its limitations, the use of sexed semen has the potential to accelerate genetic progress. It creates an opportunity to increase the production rate of quality replacement cows with enhanced genetic traits, and thus alter the economic landscape of the dairy industry.

\section{Acknowledgements}

The authors are grateful to the Ministry of Science and Technological Development of the Republic of Serbia for sponsoring part of the study within project No. TR31086. This research was supported by the 9877-3/2015/FEKUT grant of the Hungarian Ministry of Human Resources.

\section{References}

Bodmer, M., Janett, F., Hässig, M., Daas, N., Reichert, P. and Thun, R. (2005): Fertility in heifers and cows after low dose insemination with sex-sorted and non-sorted sperm under field conditions. Theriogenology 64, 1647-1655.

Cerchiaro, I., Cassandro, M., Dal Zotto, R., Carnier, P. and Gallo, L. (2007): A field study on fertility and purity of sex-sorted cattle sperm. J. Dairy Sci. 90, 2538-2542.

Cundiff, L. V., MacNeil, M. D., Gregory, K. E. and Koch, R. M. (1986): Between and withinbreed genetic analysis of calving traits and survival to weaning in beef cattle. J. Anim. Sci. 63, 27-33.

DeJarnette, J. M., Leach, M. A., Nebel, R. L., Marshall, C. E., McCleary, C. R. and Moreno, J. F. (2011): Effects of sex-sorting and sperm dosage on conception rates of Holstein heifers: Is comparable fertility of sex-sorted and conventional semen plausible. J. Dairy Sci. 94, $3477-3483$.

DeJarnette, J. M., Nebel, R. L. and Marshall, C. E. (2009): Evaluating the success of sex-sorted semen in US dairy herds from on farm records. Theriogenology 71, 49-58.

De Vries, A., Overton, M., Fetrow, J., Leslie, K., Eicker, S. and Rogers, G. (2008): Exploring the impact of sexed semen on the structure of the dairy industry. J. Dairy Sci. 91, 847-856.

Foote, R. H. (2010): The history of artificial insemination: Selected notes and notables. J. Anim. Sci. 80, 1-10.

Garner, D. L. and Seidel, G. E. (2008): History of commercializing sexed semen for cattle. Theriogenology 69, 886-895. 
Gregory, K. E., Bennet, G. L., Van Vleck, L. D., Echternkamp, S. E. and Cundiff, L. V. (1997): Genetic and environmental parameters for ovulation rate, twinning rate, and weight in a cattle population for twinning. J. Anim. Sci. 75, 1213-1222.

Healy, A. A., House, J. K. and Thomson, P. C. (2013): Artificial insemination field data on the use of sexed and conventional semen in nulliparous Holstein heifers. J. Dairy Sci. 96, 1905-1914.

Mee, J. F. (1991): Factors affecting the spontaneous twinning rate and the effect of twinning on calving problems in nine Irish dairy herds. Irish Vet. J. 44, 14-20.

Meyer, C. L., Berger, P. J. and Koehler, K. J. (2000): Interactions among factors affecting stillbirths in Holstein cattle in the United States. J. Dairy Sci. 83, 2657-2663.

Nelsen, T. C., Short, R. E., Urick, J. J. and Reynolds, W. L. (1984): Genetic variance components of birth weight in a herd of unselected cattle. J. Anim. Sci. 59, 1459-1466.

Norman, H. D., Hutchison, J. L. and Miller, R. H. (2010): Use of sexed semen and its effect on conception rate, calf sex, dystocia and stillbirth of Holsteins in the United States. J. Dairy Sci. 93, 3880-3890.

O'Ferrall, G. J. and Ryan, M. (1990): Beef crossing: effects of genotype of the foetus on the performance of dairy cows. Irish J. Agr. Res. 29, 101-108.

SAS (2013): SAS Version 9.1.3. SAS Institute Inc., Cary, NC, USA.

Seidel, G. E. (2003): Sexing mammalian sperm - intertwining of commerce, technology, and biology. Anim. Reprod. Sci. 79, 145-156.

Seidel, G. E. (2007): Overview of sexing sperm. Theriogenology 68, 443-446.

Seidel, G. E. and Garner, D. L. (2002): Current status of sexing mammalian spermatozoa. Reproduction 124, 733-743.

Seidel, G. E., Schenk, J. L., Herickhoff, L. A., Doyle, S. P., Brink, Z. and Green, R. D. (1999): Insemination of heifers with sexed sperm. Theriogenology 52, 1407-1420.

Steinbock, L. A., Näsholm, A. B., Berglund, K. and Philipsson, J. (2003): Genetic effects on stillbirth and calving difficulty in Swedish Holsteins at first and second calving. J. Dairy Sci. 86, 2228-2235.

Tubman, L. M., Brink, Z., Suh, T. K. and Seidel, G. E. (2004): Characteristics of calves produced with sperm sexed by flow cytometry cell sorting. J. Anim. Sci. 82, 1029-1036.

Weigel, K. A. (2004): Exploring the role of sexed semen in dairy production systems. J. Dairy Sci. 87, 120-130.

Zadeh, G. H., Javaremi, A. N., Miraei-Ashtiani, S. R. and Kohram, H. (2008): An observational analysis of twin births, calf stillbirth, calf sex ratio, and abortion in Iranian Holsteins. J. Dairy Sci. 91, 4198-4205. 